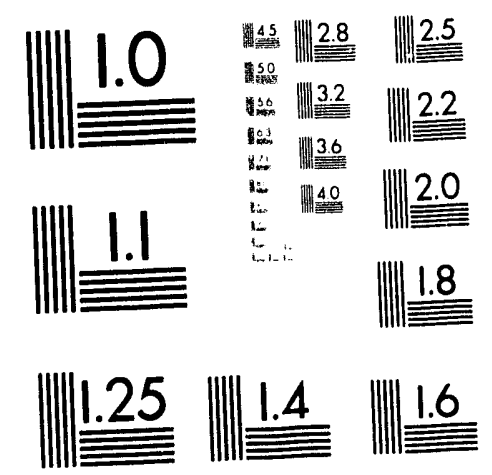



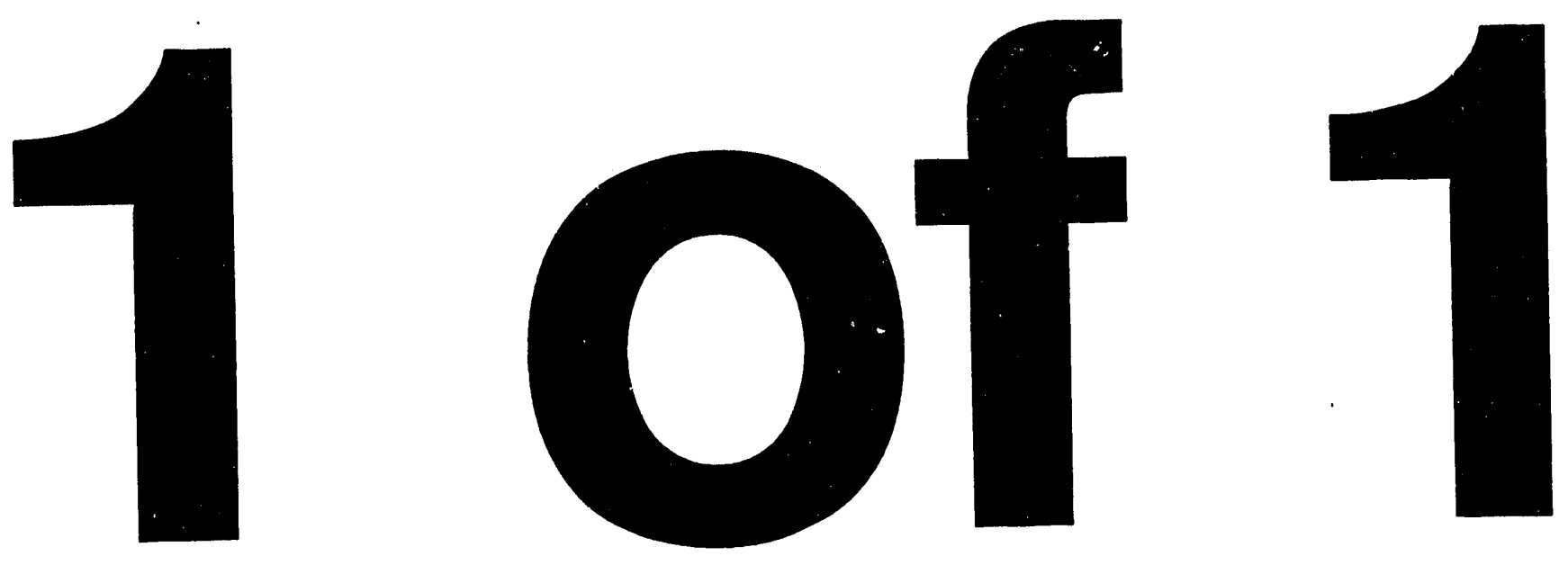


\title{
Initial Testing of the Tritium Systems at the Tokamak Fusion Test Reactor*
}

\author{
J. L. Anderson, R. A. P. Sissingh, C. A. Gentile, R. L. Rossmassler, \\ R. T. Walters, and D. R. Voorhees \\ Princeton Plasma Physics Laboratory \\ P.O. Box 451, Princeton, New Jersey 08543
}

\begin{abstract}
The Tokamak Fusion Test Reactor (TFTR) at Princeton will start its D-T experiments in late 1993, introducing and operating the tokamak with tritium in order to begin the study of buming plasma physics in D-T. Trace tritium injection experiments, using small amounts of tritium will begin in the fall of 1993. In preparation for these experiments, a series of tests with low concentrations of tritium in deuterium have been performed as an initial qualification of the tritium systems. These tests began in April 1993. This paper describes the initial testing of the equipment in the TFTR tritium facility.
\end{abstract}

\section{INTRODUCTION}

The tritium facility at TFTR, in Fig. 1, consists of: - The Tritium Storage and Delivery System (TSDS) is enclosed in three gloveboxes, the Tritium Receiving and Analytical, the Tritium Storage and Delivery and the Vacuum Pumping gloveboxes. The purpose of this system is to receive, analyze and store tritium and to deliver tritium to the injection systems on the tokamak.

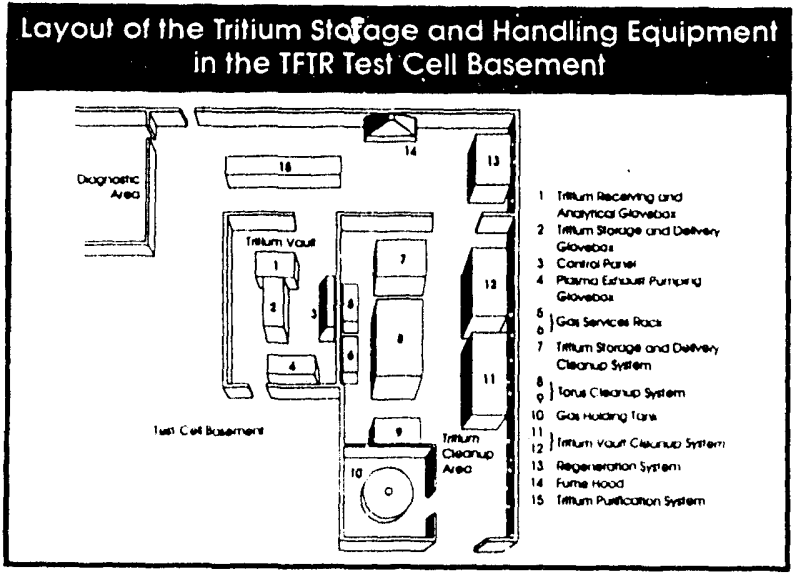

Fig. 1 TFTR Tritium Area Layout

- The Torus Cleanup System (TCS) is a $24 \mathrm{std} .1 / \mathrm{s}$ cleanup system which receives the gas from the various vacuum systems on the tokamak, and processes this gas to remove and collect the tritum contained in this gas. This system catalytically oxidizes the tritium and the resultant tritiated water is collected on molecular sieve beds for offsite shipment.

- The Tritium Vault Cleanup System (TVCS) is a 472 std. 1/s cleanup system capable of processing the atmosphere in the various rooms of the tritium facility in the event of a tritium release into these areas.
- The Tritium Storage and Delivery Cleanup System (TSDCS) is a 4.7 std. 1/s cleanup system for maintaining a dry, inert, tritium free atmosphere in the TSDS glovebox. The glovebox atmosphere is also maintained oxygen free by use of a coppus geuter bed to remove oxygen.

- The Tritium Regeneration System (TRS) is used during regeneration of the oxygen getter bed and the molecular sieve drier beds in the cleanup systems. This is accomplished in the TRS by circulating a high temperature regeneration gas through the fixed molecular sieve beds, and by reducing the copper oxide by circulating a high temperature hydrogen stream through the oxygen getter bed.

These systems have been described previously [1]. They were designed and fabricated in the late 1970's, installed in 1982 and have been in non-tritium operation since 1990. Except for the TRS, they have now been tested with hydrogen and/or tritium during the Tritium Systems Tests at TFTR.

\section{TRITIUM SYSTEMS TESTS}

In April 1993 an Operational Readiness Review approved the introduction of up to 1000 Curies $(\mathrm{Ci})$ of tritium at TFTR to be used to conduct the Tritium Systems Tests. This is a series of tests to leak check the systems with tritium, perform functional testing of the equipment with tritium, allow the operating staff to gain "hands-on" tritium experience and to begin to establish a data base of operations of the facility with tritium. A series of Integrated Systems Test Procedures (ISTPS) were written and approved for conducting the Tritium Systems Tests. These ISTPs were: ISTP-191 "Receiving, Unloading, and Inventory of Tritium for Tritium Systems Test"; ISTP-192, "Tritium Manipulation in the Tritium Storage and Delivery System"; ISTP-193, "Tritium Manipulation Between the Tritium Storage and Delivery System and the Tritium Storage and Delivery Clcanup System"; and ISTP-194, "Tritium Manipulation in the Torus Cleanup System".

In anticipation of the tritium tests, the cleanup systems, TCS, TSDCS and TVCS, had undergone testing with hydrogen to measure the cleanup efficiency (Decontamination Factor) for removing elemental hydrogen isotopes from a gas stream. These hydrogen tests were performed using a gas chromatograph as an analytical tool for detecuing elemental hydrogen in the input and output streams of the cleanup systems. These tests yiclded results showing that all of the cleanup systcms had Decontamination Factors in excess of the design requirement of 1000 .

In these hydrogen tests, a known amount of hydrogen gas was injected in front of the catalytic recombiner on the respective cleanup systems. Elemental hydrogen was measured on the outlet of recombiner and moisture was 
measured on the outlet of the drier beds. Analysis of the ' elemental hydrogen was by gas chromatography. Staff from the Tritium Systems Test Assembly (TSTA) at Los Alamos National Laboratory participated in the tests and provided the gas chromatography equipment and expertise.

Detailed test procedures were prepared, in accordance with established administrative procedures and DOE Orders, to control the movement of the tritium in the Tritium Systems Tests. All of the tritium systems had been leak tested previously with a helium mass spectrometer type leak detector and confirmed to have no single leak to the atmosphere $>10^{-6} \mathrm{scc} / \mathrm{s}$. Tritium leak checking, using a monitor as the detector, has a higher sensitivity than helium for leak checking.

\section{LSTP-19]:}

A container with a gas mixture of 10 liters of deuterium containing $-100 \mathrm{Ci}$ of tritium was prepared at the Tritium Systems Test Assembly (TSTA) at the Los Alamos National Laboratory, and was shipped to TFTR for these tests. This gas mixture was used to perform a series of Integrated Systems Test Procedures (ISTPs) at TFTR. The tritium container was moved into the Tritium Receiving Glovebox and ISTP-191 was conducted. The gas $(-0.5 \%$ tritium) was analyzed and transferred to the uranium bed-1 (UBED-1) in the TSDS. At TFTR the analysis of tritium generally is performed by mass spectrometry, beta scintillation, metal gettering techniques and ion chamber measurements. An Extrel quadrupole mass spectrometer (QMS) is operated in low resolution mode in conjunction with a SAESTM metal getter appendage pump and EG\&G Mound Labs Model MD-200 Beta Scintillator detector (BS). Calibrations of the QMS are made using pure gases and appropriate calibrated gas mixes. Total gas quantity is determined by PVT measurements.

\section{LSTP-192:}

A block diagram of the TSDS, indicating major components, is shown in Fig. 2. UBED-1 was then heated to produce a pressure of about 2400 Torr of the test gas above the UBED. This gas was then used to perform ISTP-192. Section by section, adjacent portions of TSDS were opened up to this gas while maintaining the gas pressure above 1500 Torr. Leak testing of this system was conducted using the glovebox monitor (Overhoff Technology Corporation) with a sensitivity of $1 \mu \mathrm{Ci} / \mathrm{m}^{3}$ with its inlet connected to a stainless steel probe through plastic tubing as described in [2]. Each valve bonnet, gasket flange, and welded joint was "sniffed" to detect any tritium leaks. The total quantity of test gas available was insufficient to pressurize more than half the TSDS at one time. The test was, therefore, halted temporarily to cool the uranium bed and reabsorb the tritium for pressurizing the second half of the system. In all, only one valve bonnet was observed to be leaking ; the bonnet nut was tightened and no further leak was detected. At no time did the test pressure in any open section drop below 1500 Torr. No leaks, other than the one mentioned above were detected. The glovebox monitor showed that the integrated loss from the system did not raise the glovebox background level significantly.

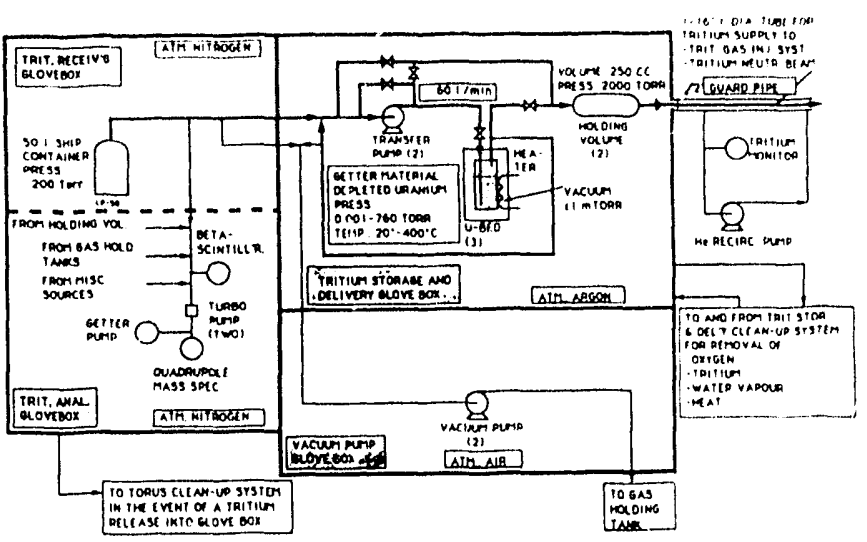

Fig. 2 TFTR Tritium Storage and Delivery System

\section{ISTP-193:}

Once the TSDS process was tested, the glovebox itself was tested with the $0.5 \%$ tritium gas using ISTP193. Here, tritium gas was trapped at a known volume and pressure between two valves and later swept into the glovebox with helium gas. A total of $26 \mathrm{mCi}$ were transferred to the glovebox in this manner. A sinall fan was used to achieve homogeneity in the glovebox atmosphere. The tritium concentration in the glovebox was measured at $13,600 \mu \mathrm{Ci} / \mathrm{m}^{3}$ by the glovebox monitor. The glovebox was placed in a static condition (isolated from the cleanup system) at atmospheric pressure for leak testing. Sniffing of all glove ports, windows, and glovebox joints indicated no leakage detectable with a handheld Scintrex tritium monitor with a sensitivity of 1 $\mu \mathrm{Ci} / \mathrm{m}^{3}$. Subsequently, glovebox pressure was raised to slightly above atmospheric pressure with argon. No lcaks were detected at this pressure.

This tritium was then used as a source of elemental (DT) tritium for leak testing the Tritium Storage and Delivery Cleanup System (TSDCS), Fig. 3. The TSDCS was connected to the TSDS glovebox to circulate the glovebox atmosphere while maintaining the platinum catalyst in the recombiner at less than $35^{\circ} \mathrm{C}$. This precaution was taken to permit elemental tritium to reach the discharge side of the molecular sieve drier beds in the TSDCS. Recirculation of this gas back to the TSDS glovebox showed an equilibrium level of about $34 \mu \mathrm{Ci} / \mathrm{m}^{3}$ in the glovebox (about twice the background level). No leaks greater than $10 \mu \mathrm{Ci} / \mathrm{m}^{3}$ above background were detected using the handheld Scintrex monitor to sniff a!l TSDCS flanges, valve bonnets, gaskets and welds. This test procedure was then repeated to provide a source of tritium for testing TSDCS with a hot recombiner $\left(\sim 175^{\circ}\right.$ C). Glovebox tritium concentration, as a function of time, is shown in Fig. 4. No tritium was observed at the discharge of TSDCS, so a decontamination factor was calculated to be over 4000 , consistent with results obtained when TSDCS was tested with hydrogen.

\section{ISTP-194:}

The Torus Cleanup System (TCS) was then tested using ISTP-194. Approximately $800 \mathrm{mCi}$ of tritium were transferred from UBED-1 in the TSDS to the Gas Holding Tank in the TCS, Fig. 5. The handheld monitor was used to sniff all flanges, welds and valve bonnets during the 
transfer operation, and during GHT sampling and analysis operations. No leaks were detected. Approximately 200 $\mathrm{mCi}$ were then introduced into the TCS and recirculated while maintaining the recombiner catalyst cold. Once elemental tritium levels at the TCS discharge point exceeded dischargeabie levels, the addition of tritium was

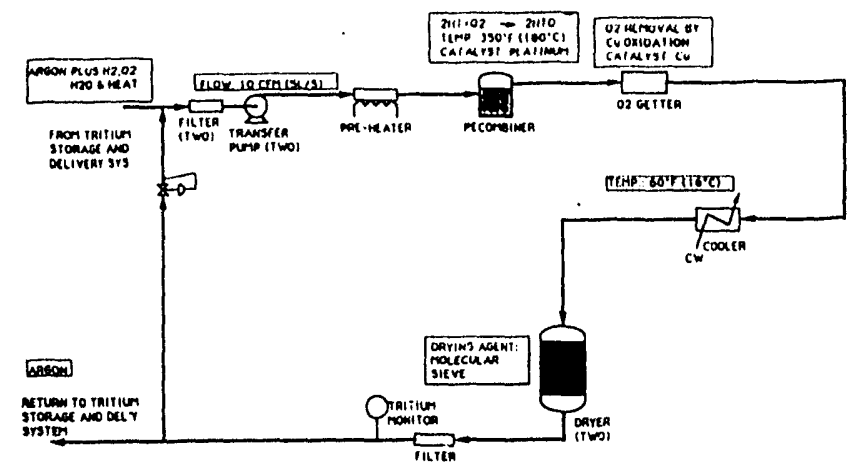

Fig. 3 Tritium Storage and Delivery Cleanup System

stopped and leak checking of the TCS was initiated, while maintaining the recirculating flow through the TCS. Again, no leaks were detected. Finally, upon completion of the leak checking, the TCS recombiner temperature was raised and the recirculating tritium was cleaned up. The three phases of this test are clearly shown in Fig. 6: initial buildup due to introduction of tritium; slow decay due to equilibration and plating out within TCS; and finally, very rapid cleanup once the recombiner temperature approached $175^{\circ} \mathrm{C}$. Subsequent cleanup of approximately $580 \mathrm{mCi}$ at a recombiner temperature of about $500^{\circ} \mathrm{C}$ showed no tritium in the TCS outlet, consistent with the results obtained during testing with a nominal $1 \%$ hydrogen in nitrogen mixture. This implies a decontamination factor well over 1000 .

\section{TRITIUM INVENTORY}

As a final test, all of the tritium on the uranium beds in the TSDS was desorbed and sent to the Gas Holding Tank (GHT) in the TCS. A total of about $117 \mathrm{Ci}$ were transferred at this time. The measurement of tritium in the GHT (about $7.6 \mathrm{~m}^{3}$ ) was by a Femto-tech ${ }^{T M}$ model $2524 \mathrm{PP} / \mathrm{U} 24$ tritium monitor in a sample recirculating loop. This monitor had been calibrated, by Los Alamos National Laboratory, at concentrations from 1 to 20 $\mathrm{Ci} / \mathrm{m}^{3}$. The measured concentration in the GHT during this test was about $13.5 \mathrm{Ci} / \mathrm{m}^{3}$. This gas in the GHT was processed through the TCS, collecting the tritiated water on the fixed molecular sieve beds in the TCS. No leaks were detected while processing this higher concentration gas. No tritium was detected at the outlet of the molecular sieve beds. Thus both the leak tightness and the functionality of the TCS were demonstrated during this test.

When the $117 \mathrm{Ci}$ of tritium were transferred from the TSDS to the Gas Holding Tank in the TCS a problem was encountered. Intially, the tritium monitor on the GHT measured much less than $117 \mathrm{Ci}$. Several activities were initiated to determine the cause for this discrepancy. First, the tritium monitor on the GHT was suspect. A spare, identical monitor was available. This monitor was sent to
LANL for calibration with tritium gas in the range 1-20 $\mathrm{Ci} / \mathrm{m}^{3}$. Second, all of the vacuum piping between the uranium beds and the GHT was purged with nitrogen to the GHT. Also, the decision was made to sample and analyze oil in the vacuum pump used to pump the test gas into the GHT. During the maintenance operation to sample the pump oil some $11 \mathrm{Ci}$ of tritium were released to the plant stack, and a small amount $(<1 \mathrm{Ci})$ was released into the tritium vault. The tritium in the vault actuated the alarm

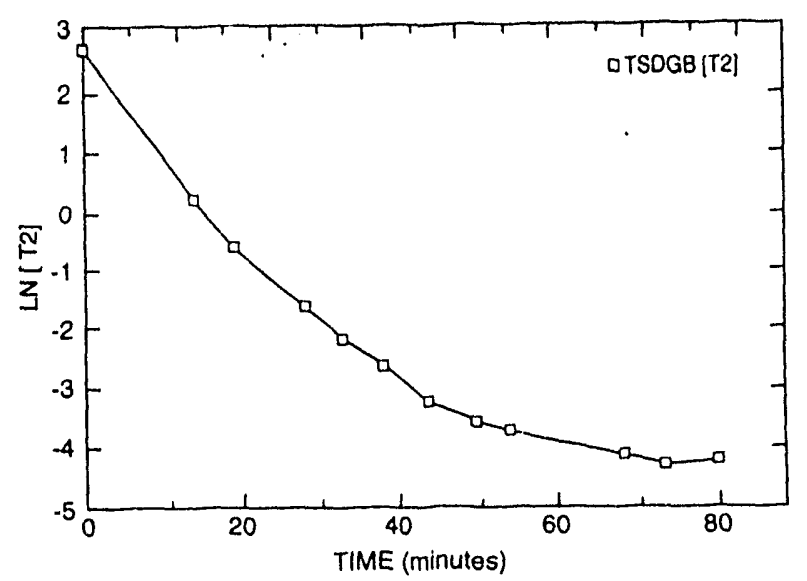

Fig. 4 TSDGB Cleanup, initial tritium load was 26 $\mathrm{mCi}$.

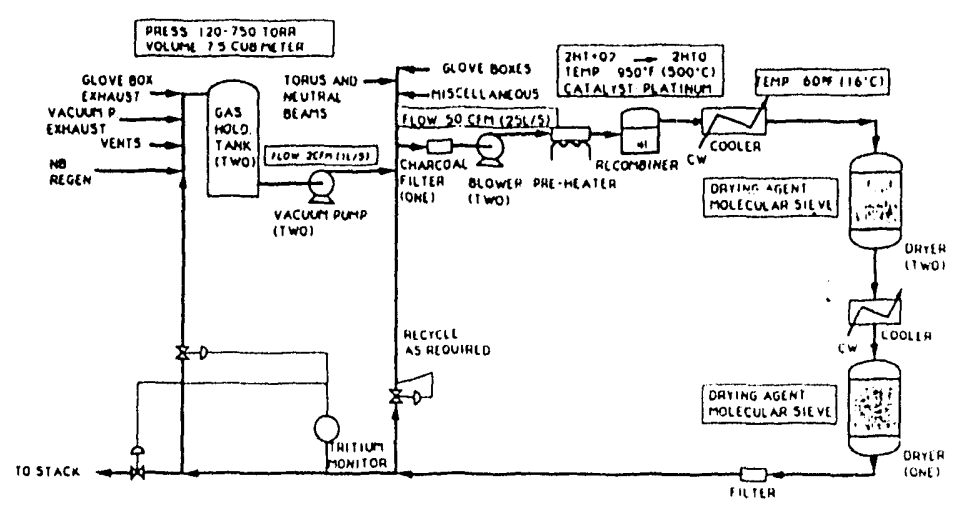

Fig. 5 Torus Cleanup System

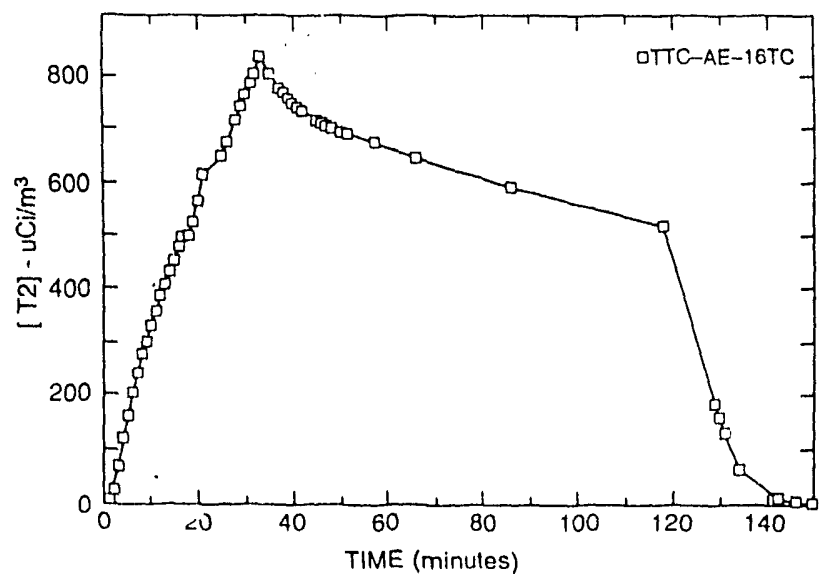

Fig. 6 Tritium concentration at oullet of TCS during ISTP-194 
on the area (room) monitor and this activated the Tritium, Vault Cleanup System (TVCS). The TVCS quickly cleaned the vault atmosphere, removing the tritium by oxidation to form tritiated water and collecting the tritiated water on molecular sieve. This was an unplanned test of the TVCS, but in fact demonstrated that the system works as designed.

Upon completion of the calibration of the second monitor at Los Alamos, this monitor was installed on the GHT and used to analyze the contents. Measurements taken with the calibrated monitor proved that all of the tritium was indeed in the GHT and that the original monitor installed on the GHT had not been functioning properly.

At the conclusion of these tests, a summary of the tritum inventory data was generated. Table 1 su'nmarizes the inventory data. These data show that all of 'the tritium introduced into the TSDS from the originai shipping container has been identified and measured at the end of the experiment. The $-6 \mathrm{Ci}$ identified as Process Holdup has not been measured, but is inferred by difference. The DOE level of accountability for tritium is to the nearest $0.01 \mathrm{~g}$ $(100 \mathrm{Ci})$. These data show that the measurements at TFTR are at a much higher sensitivity than required by DOE for inventory control.

Table I

INVENTORY SUMMARY

Tritium Systems Test

\section{CURIES}

Recieved from LANL

125.8

Transferred to Tritium System

121.6

Residual Gas Left in Shipping Container

Current Location of Tritium

Used In Tritium Systems Test:

\section{CURIES}

Torus Cleanup System

Gas Holding Tank A

Gas Holding Tank B

Residual on U-Bed 1

Stack Release

Process Holdup (not measured)

Total Ending Tritium
System. Testing the TVCS had not been an objective of these tests, however, this event demonstrated that the TVCS does operate and function as designed.

These tests were conducted with slightly over $100 \mathrm{Ci}$ of tritium. At the end of the test, we were able to account for all of the tritium, thus demonstrating measurement capability well in excess of that required by current DOE requirements for inventory control. Through these tests the operating staff at TFTR have gained valuable "hands-on" tritium experience. With this series of tests successfully completed, the tritium staff at TFTR is now ready to proceed with expanding the tritium boundary up to and into the tokamak and into the vacuum systems.

\section{ACKNOWLEDGMENTS}

Many TFTR engineers, scientists, technicians and Tritium Operators helped in the planning and execution of these tests. Without their dedicated and tireless contribution, we would not have been able to conduct this work. We are also appreciative of the help of Dr. Scoll Willms, LANL, in conducting the hydrogren tests on the cleanup systems and Mr Dick Olsher and his staff at LANL for calibrating our Femto-tech monitor.

This work was supported by US DOE Contract \#DEAC02-76-CHO-3073.

\section{REFERENCES}

11] R. A. P. Sissingh and R. L. Rossmassler, "Tritium facility at TFTR", Fus. Eng. and Design, Vol. 12, pp. $383-391,1990$.

[2] J. L. Anderson, D. O. Coffin, R. A. Jalbert, J. E. Nasise, and R. H. Sherman, "Some tips on tritium technology", Fusion Technol. , Vol. 8, \#2, pp. 2413. $2419,1985$.

\section{CONCLUSIONS}

The Tritium Systems Tests on the TFTR tritium systems have been completed successfully. No major leaks or equipment failures were detected in the primary tritium systems. One relatively small leak was corrected by tightening a valve bonnet nut. During a maintenance operation, a small $(11 \mathrm{Ci})$ tritium release occurred. This resulted in activation of the Tritium Vault Cleanup 


\section{IEEE COPYRIGHT FORM}

This form is intended for original, previously unpublished manyscripts submitted o IEEE periodicals and conterence publications. The signed form, appropriately completed, MUST ACCOMPANY any such paper in order to be published by IEEE. Please read all notes overleat and keep a copy of both sides for your files.

TITLE OF PAPER (hereinatter, "The Work"):

Initial Testing of the Tritium

SIGNED FORM SHOULD

ACCOMTANY MSS. OR BE

SENT TO SAME ADDRESS

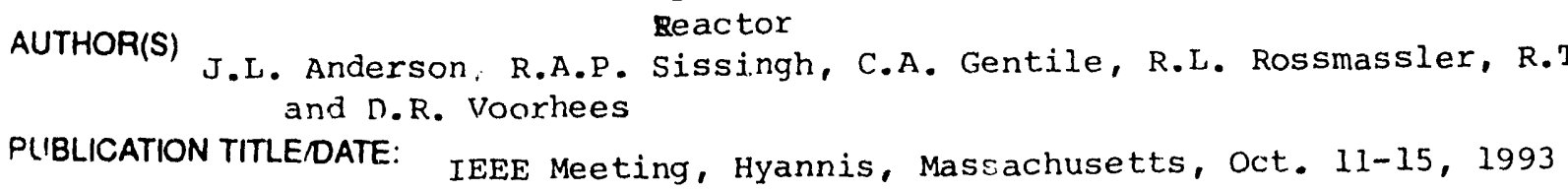

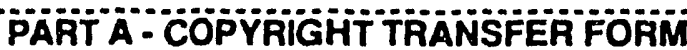

(Nole: Company or other lorms MAY NOT BE SUBSTITUTED lor this lom. WORDING MAY NOT BE CHANGED. U.S.Govemment employees whose work is not subject to U.S. copyright may so cortify by signing Part B below. Authors of works subject to Crown Copyright may sign Part C overleat.)

The undersigned hereby transfer any and all rights in and to The Work including without limitation all copyright rights in the above Work to The Institute of Electrical and Electronics Engineers, Inc., known as the IEEE. The undersigned hereby represents and warrants that The Work is original and that he/she is the author of The Work or otherwise has the power and authority to make and execute this assignment.

Beturned and Retained Biahts: In return for these rights, the IEEE recognizes the retained rights noted in items 1 and 5 below and grants to the above authors and employers for whom the work was performed royalty-free permission to reuse their material as noted in items 2, 3, and 4.

1. Employers (or authors) retain all proprietary rights in any process, procedure, or article of manufacture described in The Work.

2. Authors may reuse all or portions of the above Work in other works. (See "Author/Employer Rights" overieaf.)

3. Authors/employers may reproduce or authorize others to reproduce the above Work (or derivative works) for the author's personal use or for internal company use provided that the source and the IEEE copyright notice are indicated, that the copies are not used in any way that implies IEEE endorsement of a product or service of an employer, and that the copies per se are not offered for sale. (See "Author/Employer Rights" overleaf .)

4. Authors/employers may make limited distribution of all or portions of the above Work prior to publication if they inform the IEEE of the nature and extent of such limited distribution prior thereto.

5. In the case of work performed under a U.S. Government contract or grant, IEEE recognizes that the U.S. Government has royalty-free permission to reproduce all or portions of the above Work, and to authorize others to do so, for official U.S. Government purposes only, if the contract/grant so requires. (Appropriate documentation may be attached, but IEEE's Copyright Transter form MUST BE SIGNED. See "U.S. Government EmployeesN.S. Government Contract Work" overleaf.)

Please see overieaf for notes on "IEEE Obligations" as copyright holder.

In the event the above paper is not accepted and published by the IEEE or is withdrawn by the author(s) before acceptance by the IEEE, this agreement becomes null and void.

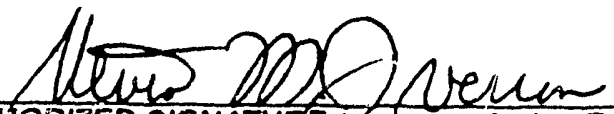

This will certify that all authors of the above Work are employees of the U.S. Government and performed this work as part of their official duties and that the Work is therefore not subject to U.S. copyright protection.

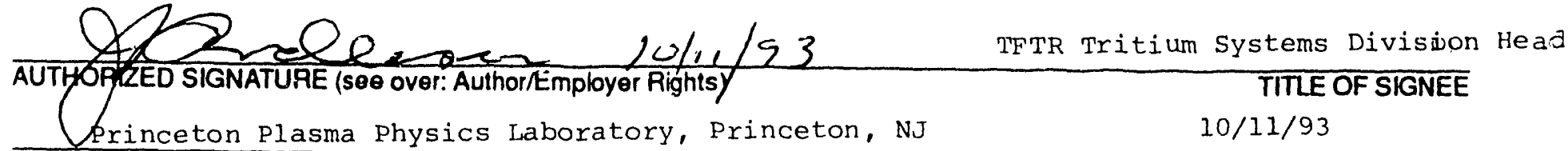




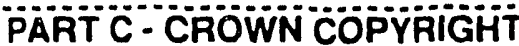

(Note: IEEE recognizes and will honor Crown Copynght as it does U.S. Copyright. It is understood that, in asserting Crown Copyright, IEEE in no way diminishes its rights as publisher. Sign only it $\mathcal{A L L}$ authors are subject to Crown copyright.)

This will certify that all authors of the above Work are subject to Crown Copyright. (Appropriate documentation and instructions regarding form of Crown Copyright notice may be attached.)

AUTHORIZED SIGNATURE (se日 bolow: Author/Employer Rights) TITLE OF SIGNEE

NAME OF GOVERNMENT BRANCH

IEEE POLICY

Notes and information for Authors and Their Employers

In connection with its publishing activities, it is the formal policy of the IEEE to own the copyrights to all copyrightable material in its technical publications, and to the individual contributions contained therein, in order to protect the interests of the IEEE, its authors and their employers, and, at the same time, to facilitate the appropriate re-use of this material by others. The IEEE distributes its technical publications throughout the world and does so by various means such as hard copy, microfiche, microfilm and electronic media. also abstracts and may translate its publications, and articles contained therein, for inclusion in various compendiums and similar publications, otc. When an articlo is submitted for publication to the IEEE, the IEEE understands that its acceptance of the article implies that IEEE has the rights to do all of the things it normalty does with such an article.

The following formal IEEE policy applies to all material submitted to IEEE:

IEEE Policy 6.17 - Cl EARANCE OF PAPERS

The IEEE must of necessity assume that material presented at its meetings or submitted to its publications is property available for general dissemination to the audiences these activities are organized to serve. It is the responsibility of the authors, not the IEEE, to determine whether disciosure of their material requires the prior consent of other parties and, if so, to obtain it.

Funthermore, IEEE must assume that, it an author uses within his/her article previously published and/or copyrighted material that permission has been obtained for suct use and that any required credit lines, copyright notices, etc. are duly noted.

\section{IEEE OBLIGATIONS}

In exercising its rights under copyright, the IEEE will make all reasonable efforts to act in the interests of the authors and employers as well as in its own interest. In handling third party reprintrepublication requests for an IEEE work. IEEE requires that:

1. The consent of the first-named author be sought as a condition in granting republication (of a full paper) to others.

2. The consent of the employer be obtained as a condition in granting permission to others to re-use all or portions of a paper for promotion or marketing purposes.

\section{AUTHOREMPLOYER RKGHTS}

If you are employed and you prepared your paper as a part of your job, the rights to your paper initially rest with your employer. In that case, when you sign the copyright transfer form, we assume you are authorized to do so by your employer and that your employer has consented to all the terms and conditions of this form. If not, it should be signed by someone so authorized. (See also Policy 6.17 above.)

SPECLAL NOTE TO EMPLOYERS: Just as the IEEE requires a signed copyright transfer form (for copyrightable material) in order to do "business as usual," it is the intent of the transfer portion of the form to return rights to the author and employer so that they, too, may do "business as usual." (See rote at bottom of page re. further details.)

Please note that, although authors are permitted to reuse all or portions of their IEEE-copyrighted material in other works, this does not include granting third party requests for reprinting, republishing or other types of re-use. All third party requests must be handled by the IEEE Copyrights and Trademarks Office. (See note at bottom of page.)

\section{JOINT AUTHORSHIP}

For jointly authored papers, have all the joint authors sign, or at least have one of the authors sign as an authorized agent for the others. In the case of multiple authorship where one or more authors are Government employees but at least one author is not, that non-Government author should sign Part A of this Copyright Transfer Form.

\section{U.S. GOVERNMENT EMPLOYEESN.S. GOVERNMENT CONTRACT WORK}

Authors who are U.S. Govemment employees are not required to sign the Copyright Transfer Form, but any coauthors outside the Government are required to sign. (See JOINT AUTHORSHIP above.)

Authors whose work was performed under a U.S. Government contract or grant, but who are not Government employees are required to sign Part A of this Copyright Transfer Form.

PLEASE DIRECT ALL QUESTIONS ABOUT IEEE COPYRIGHT POLICY OR THIS FORM TO:

Manager, Copyrights and Trademarks, IEEE Service Center, 445 Hoes Lane, P.O. Box 1331, Piscataway, NJ 08855-1331. Telephone: (201) 562-3966 

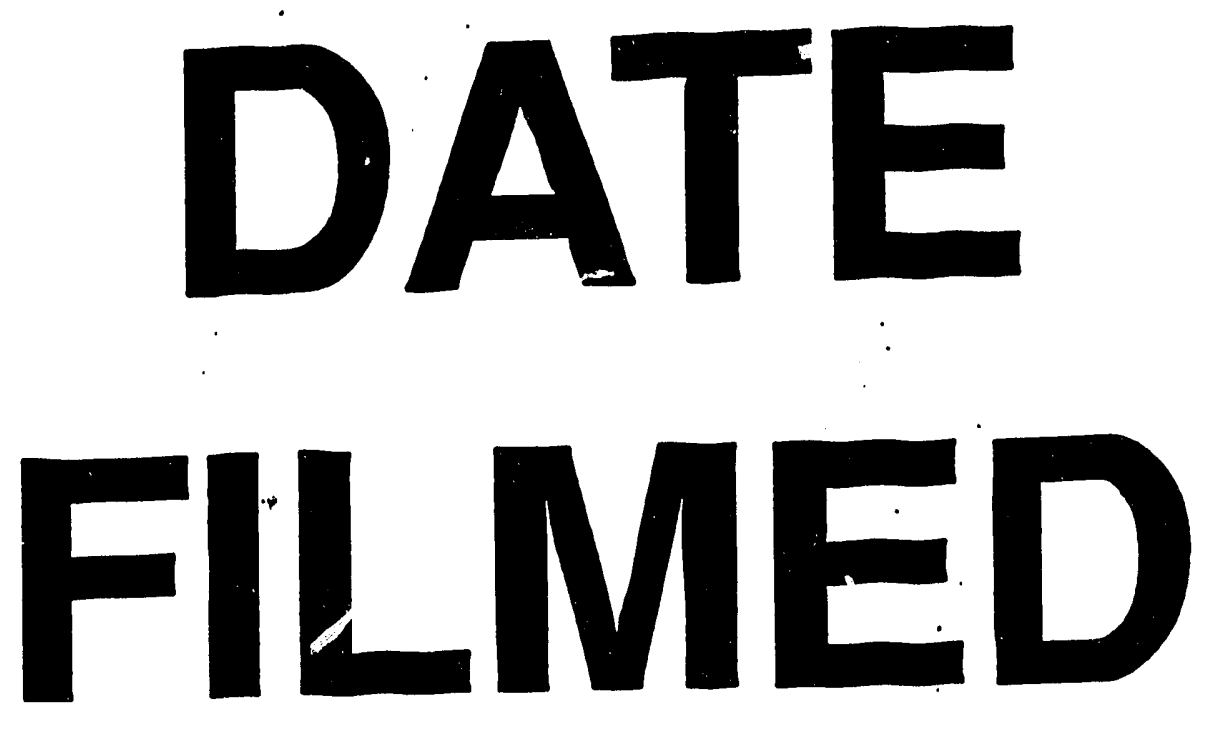

$12 / 17 / 93$
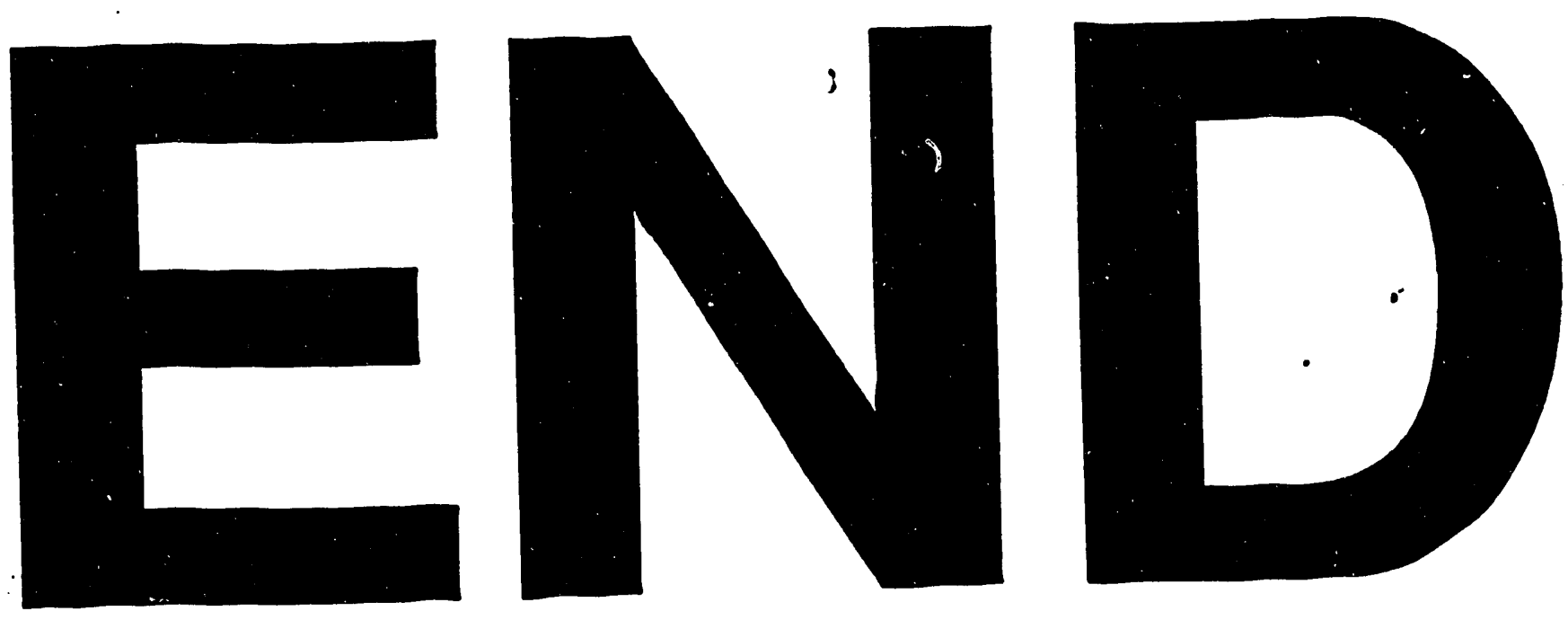
